\title{
Retraction: Iron Supplementation Decreases Severity of Allergic Inflammation in Murine Lung
}

\author{
Laura P. Hale, Erin Potts Kant, Paula K. Greer, W. Michael Foster
}

The authors of the published article have identified concerns about the reliability of a subset of the reported data, specifically the data underlying Figures 1 and 2. Potential discrepancies have been discovered between the machine-generated raw data and the data for publication provided by the murine pulmonary function laboratory, and the authors have become aware of potential issues in methodology that could make the data unreliable. Figures 3 and 4 are not affected.

In light of the concerns identified, the authors retract this publication.

\section{Reference}

1. Hale LP, Kant EP, Greer PK, Foster WM (2012) Iron Supplementation Decreases Severity of Allergic Inflammation in Murine Lung. PLoS ONE 7(9): e45667. doi:10.1371/journal.pone.0045667 PMID: 23029172

\section{G OPENACCESS}

Citation: Hale LP, Kant EP, Greer PK, Foster WM (2016) Retraction: Iron Supplementation Decreases Severity of Allergic Inflammation in Murine Lung. PLoS ONE 11(5): e0155387. doi:10.1371/journal. pone. 0155387

Published: May 9, 2016

Copyright: @ $\odot 2016$ Hale et al. This is an open access article distributed under the terms of the Creative Commons Attribution License, which permits unrestricted use, distribution, and reproduction in any medium, provided the original author and source are credited. 